Thy 热uxlen forture

$$
\text { ON }
$$

\section{THE NATURE OF DISEASE.}

Detivered at the UNiverity of Birmisgham on Femeany $12 \mathrm{TH}$

\section{BY}

SIR HLMPHRY ROTLESTON, B.IRT., K.C.B., M.D., How.D.Sc., D.C.I., LL.D.,

REGiUs PROFESSOR OF PHYSIC A THE VNIVERSTYY OF CAMBRIDGe.

Hraltu is the state of body and mind resulting from the successful adaptation of the living organism to external and internal factors. Dis-ease (want of ease), which is a departure from this condition of equilibrium or a want of harmony, -has been often defined, but the definitions have not given universal satisfaction, and, as Mercier pointed out, it is noteworthy that the fundamental concepts of other callings, such as the law, engineering, finance, and war, are also hard to define, and that this process of specification, so to speak, is not arrived at until late in their history, though their practical efficiency has not been thereby affected. Definitions are a weariness of the Hesh, but it may be well to quote one ont of manythat formulated by the late J. G. Adami in 1910-as it contrasts with that of health and gires a good indication of the potential variability in the reaction we call disease; it runs as follows, "Disease is a process or succession of disturbances indued by any agent which disturbs the normal activities of the organism as a whole or of its constituent parts." Into another definition---that " disease is a failure of adaptation both to conditions without the organism and within" (II. A. White)-may perhaps be read two additional points: first, that the responsible ause may be inside the body, quite inderendent of any extraneous factor-for example, somo congenital structura! defect or a functional aberration, such as "the inborn errors of metabolisin" or "chemiral malformations" described by Archibald Garrod: and secondly, that in the process of adaptation not only may the normal reserve power of the living body be called upon, but that in comparatively slowly developing morbid changes, such as valvular disease of the heart and narrowing of canals such as the intestine, compensatory or adaptive processes, secondary to, but keeping pace (at any rate for a time) with the morbid change, may bring about such an adjustment that there is absolute freedom from symptoms. Thus destruction of one kidney may be compensated by hypertrophy of the other, and destruction of a portion of the liver by regeneration in the remainder. Srmptoms, and disease in the sense to be explained directly, ivill only occur when these compensatory muscular and glandular hypertrophies fail; the hitherto latent morbid change then gives rise to functional disorder-that is, srmptoms. This " margin of safety" or compensatory mechanism must be borne in mind as a difficulty in attaining the desired knowledge from the study, so much insisted upon by the late James Mackenzie, of the earliest departures from health; for by the time symptoms appear the morbid changes may be well established, and the manifestations might then be wrongly regarded as functional changes leading up to, and responsible for, the structural alterations. The mechanisms which compensate or restore damaged tissues or impaired functions, though for a varying time eminently successful, tend erentually to fail and then to become harmful; thus, according to 'Thoma's histo-mechanical conception of arterio-sclcrosis, there is in the first place a local thickening of the inner coat of the artery to obriate a bulging at a spot where it would occur as the result of degeneration of the muscular middle coat; in course of time, however, the thickened area in the intima also degenerates, and what was a compensatory process becomes a morbid lesion. Further, the compensatory and defensive powers of the body may from the outset be ineffective-for example, when inflammation, defined as "the local attempt at repair of actual or referred injury" (Adami, 1896), rapidly produces suppuration; this idea is also expressed with regard to malignant disease in George Aewman and J. A. Murray's dictum that "cancer' may be considered as an aberration of the process of repair."

What is a Disease?

To consider now in rather more detail the question, What is a discase? Primitive man is superstitious and has alwars regarded disease and accident as due to the action of ain offended or malicious deity, of the dead, or to the machinations of an enemy, and from the last-belief 'was derived the idea of magic and witcheraft. Disease became regarded as a definite invasion of the body, as by demoniao possession or by a more material substance, which must be allowed an exit, as by the trephining in Neolithic times, or expelled, in order to ohtain a cure. This notion that the cause of disease was the presence in the body of a forcign spirit or of some concrete substance with an extracorporeal existence or phase obviously expresses, though in less scientific terms, the more modern knowledge of parasitic and bacterial infection, and so far may be regarded as prophetically rational. To discover the cause of the disease is the aim of diagnosis, and so keen is the appreciation of this important principle that there is still a tendency to regard the cause as synonymous with its results. A not unitural outcome of the belief that disease was a disorder with an objective reality and due to some harmful substance in the patient's body was the materialization of diseases on the lines of botanical and roological classifications, and to arrange them in genera and species after the successful plan initiated by Limnacus. For this view Thomas Sydenham (1624-1689)-the British Hippocrates-.. was in part responsible. The rival nosologies of Felix Pliter (1680), de Sauvages (1763), Vogel (1772), MacBride (1778), Willian Cullen (1785), Thomas Young (1813), John Mason Good (1817), and others elaborated this conception. Eren now diseases are spoken of, though perhaps not serionsiy so risualized, as quite definite things; and it may he asked, What practical difference does it make if they are? A partial answer is that this would logically justify a rule-of-thumb practice of treating the disease rathei than the sufferer. In this age of mass production and machine-made standardization, when, for example, motor cars are so alike that their disorders are of a stereotyped character, it is particularly important to insist on the obvious-namely, that human boings are made, not from one mould, but, individually, differing widely in their makeup and power of response. In illness we all desire to be treated as a special problem, rot as one of a crowd of Robots, and aecordingly trust our medical attendants not only for their technical knowledge but also for their ability of applying it to our particular needs. Every illness is the reaction of the body and mind of the patient to some factor which in its turn may be simple or complicated; the reactions of living matter are far from coustant, and those of man become more complex as he moves from childhood and the simple life of the country to maturity and the whirlpools of nodern civilization. Thus a startling or offensive announcement may leave one man untouched because ho is deaf; another, phlegmatic or a philosopher, mav receive it in silence; whereas in a third an emotional explosion follows. This variation in the response is most dramatically seen in idiosyncrasies, such as asthma and hay fever, as the result of inhalation of horse emanations or of pollens, or of abdominal and cutaneous symptoms, as the result of eating a few specks of parsley-an example of which in four generations of a family has just been brought to my notice. As in other matteis, the problem, much discussed more than sixty years ago by Handfield Jones, Wilks, and W. Broadbent, whether to treat the disease by routine methods or the patient, is best solved by a compromise of judicious combination; for to treat the man without anr reference to his malady-for example, if he is weak and his strength failing to be content with giving alcoholic or other stimulants-would be to regard one side only of the shield, prone to abuse and therefore very likely to do him definite harm.

But to continue consideration of the question what is meant by a disease. As long ago as 300 B.c. Erasistratus of the Alexandrian School of Medicine regarded it as a perression of health, of the normal processes, and not a 
condition contrary or foreign to biological nature; but this was forgotten. In modern times Claude Bernard (1854) spokso of disease as a physiological reaction in altered (1reumstances, and Clifford Allbutt, since 1871, followed by (C. A. Mercier and F. G. Crookshank, pleaded for clear thinking and the recognition that a disease is not a clefinite thing, like a plant, but a mental abstraction or concept of the reactions of a living organism in certain circumstances. The groups of reactions form distinct pictures in the nind and are labelled by the name of a disease.

What a Disease is Not.

Before going further it may clear the ground to consider what a disease is not; although a patient is ordinarily spoken of as, say, a case of cancer of the stomach, the malignant growth is not the disease; for disease is the reaction of the living body in the form of functional disorder's correlated with a cause, whereas the cancerous stomach persists after death. Disease, like health, is inseparable from life, and its nature and causation would no doubt be differently interpreted by those holding the vitalistic and the mechanistic explanations of life.* Further, gross structural change may exist, and yet, as tho result of compensatory changes, not cause any disturbance of function or symptoms of disease; conversely, changes such as can at present be recognized by the naked eye and the microscope may be absent in disease, although it is reasonable to imagine that some alterations occur, just as they must in other forms of vital activity. Symptoms, though the manifestations of the reaction and so part of a disease, do not of themselves constitute a definite disease, for they may be due to several causes rather than to one. In the case of infective diseases the exciting cause is invasion of the body by micro-organisms, tio toxins of which set up changes in the body and so the resulting reaction called the disease. But the manifestations of the reaction may bo regarded as of two kinds and as possibly due to two mechanisms: (1) as Boycott points out, the general symptoms, such as malaise, fever, and headache, common to most infections, are mainly due to substances liberated from the injured cells of the tissues; (2) the manifestations specially characteristic, and so diagnostic of certain infective agents, may be due more to specific bacterial toxins-for example, tetanus toxin, acting directly on the body tissues; or conceivably, as Sidney Martin argued year's ago, the bacteria may produce a ferment which acts on the cells of the body so that they manufacture a specific poisonous substance. Symptoms have in the past been regarded as diseases-for example, dropsy-and even in our own day it has become recognized that some conditions, such as epilepsy, are collections of symptoms due to different factors; lience it is more correct to speak of the epilepsies rather than of epilepsy. To collections of symptoms occurring in conjunction sufficiently often to render their correlation recognized, but without any constant single underlying cause, the names " syndrome" and "symptom-complex" have been applied; the distinction between a syndrome and a disease, as the words are usually employed, is to be found in their. etiology. A distinction has also been drawn between "syndrome," or a collection of symptoms with a functional or anatomical basis in the body, and the more modern word "symptom-complex," $\dagger$ which implies a series of clinical signs and symptoms without any consideration of their relationship to a lesion or functional disorder of an organ, or a purely clinical coincidence (Cawadias). The word " symptom-complex," which has not escaped criticism as a barbaric mixture of the two classical languages, was, according to the Oxford Dictionary, first used in this country. in 1897. As Cawadias points out, diseases were really synptom-complexes from Hippocratic times to the

* Aigusta Gaskell, who argues that life is due to the permeation by an immaterial system (derived from protons and electrons) of a material atomic system composed of chemical units, believes that the phenomen of cancer " constitute a striking proof " of her hypothesis.

+ Mercier in 1917 ponred scorn on "the terms syndrome, symptomcomplex, and other monstrosities made in Germany" as "on a par with the exploit of the servant girl who calls a brilliant flash of lightning 'chronic,', of the alienist who calls primary dementia dementia praecnx. But the word $\left(\sigma v \nu \delta \rho \mu^{\prime}\right)$ was employed by the Empiries of symptont era of the anatomico-clinical school of Paris and of Claude Bernard and Johannes Müller (1801-58), when syndromes formed the basis of nosological classification. The term "clinical entity" is often used as synonymous with syndrome or symptom-complex to describe a definite collection of niorbid manifestations which may be due to more than one distinct cause, and so is useful as long as the causiltion is uncertain. It thus avoids the definite statement that the group of symptoms is specific-namely, due to one factor-in other words, a disease in the proper sense of that word. Objection has been raised, especially by the late Sir Clifford Allbutt, to " clinical entity" as a descriptive title for a morbid condition, because it tends to perpetuate the material conception of something analogous to demoniac possession. But though this interpretation may be literally justified, it is not, rightly or wrongly, the meaning widely attached to tho phrase.

To sum up, a disease is not a poison, a parasite, an ulcer, or a tumour, for these are causes; it is not a symptom, such as pain; but it is the mental picture of the manifest reactions of a living organism in response to harmful factors, whether derived from outside the body or arising internally.

Transitions between Health and Disease.

As disease is primarily a physiological reaction to stimulating or depressing factors of a harmful character, anc a mental concept or "construct" summarizing the events which then occur, it is clear that the line dividing healti and the defensive powers of the body from disease may be very indefinite. Thus if the defensive powers are high the necessary reaction may be so short and slight as to be unaccompanied by any symptoms, and the individual is unconscious of the inward struggle that has taken place; this process is indeed constantly in action, and constitutes the resistance of a healthy individual. Truly wo stand in jeopardy every hour. In other instances the reaction is more marked, but so rapidly successful that the disease is aborted; it is in cases in which the reaction is prolonged or eventually fails in its purpose that disease is moro decidedly present. The leucocytosis in the early stage of infection may be compared with the reactive leucocytic increase during digestion due to absorption of food. Inflammation is an entirely useful and innocent process in the healing of an aseptic wound; indeed, it comes within the four corners of Frédéric's canon of physiology-namely, that " a living being is adjusted in such manner that each perturbing influence provokes to activity a compensating apparatus which brings about neutralization and repair of the damage." No one would call this a disease, but such an inflammatory reaction may gradually become a disease; thus local peritonitis producing adhesions by shutting off an infective focus is a protective or curative process; but general peritonitis is a reaction which so often fails that the causal infection is fatal. Here it may perhaps be mentioned that somewhat similar transitions are seen in diseases which vary in the number of the symptoms; when, instead of all the symptoms recognized as making up the mental concept, a few only are present, the disease is spoken of as larval or fruste; this may be a question of time, the reaction terminating before the initial manifestations are supplemented by those necessary to complete the recognized clinical picture.

With regard to the nature of the exact vital changes which occur in disease, apart from the comparatively gross alterations revealed by the microscope, there is much to learn. The recent advances of knowledge in connexion with the constitution of the atom and the electron hold out promises of possibilities the extent of which it is difficult to forecast. The application of physical chemistry to medicine is clearly of the greatest importance, but is so beset with difficulties that attempts to do so deserve sympathetic encouragement, even though they may not as yet carry conviction or be confirmed. Auguste Lumière explains health as-due to the maintenance of the normal colloidal state, whereas disease is the result of its disturbance causing precipitation of protein from the colloids. When this occurs in the blood stream symptoms of acute disease follow, whereas chronic disease is due to precipita- 
tion in or about the cells of the tissues and organs, the different forms of chronic disease being determined by the organ or organs forming the site of this precipitation. McDonagh in his speculative essays, which are somewhat difficult to follow, brings in the electron; he describes protein particles in the blood, some of which are charged with clectrons (negative), others with protons (positive), a condition of fair equilibrium meaning health. When a poison, liacterial or otherwise, comes on the scene, the protons are reinforced and the electrons are withdrawn from the protein particles; as a result the colloid state is affected and protein particles are deposited in any one or more of the four important viscera in the following order-kidneys, brain, lungs, and liver-thus causing disease.

\section{Avolutron of Drseases.}

As diseases cannot, strictly speaking, be regarded as definite " things," it might seem illogical to speak of their evolution, and it has recently been stated that a serious attempt has not yet been made to apply the doctrine of evolution to the natural history of disease (Gill). No one, liowever, can fail to be interested in the changes that diseases have shown in the course of time, and in the forms that appear to be new and produced in certain circumstances; as long ago as 1890 an interesting work on Evolution and Disease by Sir John Bland-Sutton appeared. Some sort of an explanation of the existence of disease may perhaps be suggested, as a side issue after reading Professor A. E. Boycott's recent presidential address to the Section of Pathology of the Royal Society of Medicine; in $i t$ the capacity of self-repair is emphasized as one of the main characters of living organisms, but it is pointed out that this faculty is not, or only in a very slight degree, possessed by individual unicellular organisms. Now little or nothing, if the problematic nature of bacteriophage be excluded, is known about the diseases of unicellular organisms. Diseases and the power of self-repair have both become recognizable as the scale of animal life is traced upwards, and it is conceivable that they are closely allied forms of reaction to stimuli-the one (self-repair) successful, the other (discases) more or less ineffective. Diseases are not rigid types, but the more or less unsuccessful reactions to harmful factors, most commonly environmental; it follows, therefore, that they show considerable variations in their manifestations, especially as the reaction depends on two variable factors-the characters of (1) the host or the "soil," and (2) the unfavourable environmental factor, the "seed."

\section{Changes Associated with Civilization.}

1. In the course of his progress from primitive to civilized life man has undergone many changes, and his bodily reactions to external factors, and therefore his diseases, must, like the forms of his virtues and viens, have altered in a corresponding degree, for consideration of his surroundings would suggest that the further man moves from his savage state the more complex will the character of his disorders become. How much a change of type of disease has occurred it is difficult accurately to estimate, for the slow advances of medical knowledge might easily make it appear that the evolution of disease has been more recent and extensive than is really true. There has in fact sometimes been a tendency to exaggerate the differences between the diseases of primitive savages, about which knowledge is deficient, and those of highly civilized inhabitants of large capitals. The ancient records of disease, often ambiguous ahout the existence of conditions now fully isolated, might easily convey the impression that diseases, such as small-pox and chicken-pox, scarlet fever and measles, became distinct from each other more recently than was actually the case. The comparatively new study of diseases which can be demonstrated in human and animal remains of ancient times, or palaeopathology, in the hands of Fouquet, M. A. Ruffer, Elliot Smith, and Wood Jones in Egypt, and of R. L. Moodie in America, has thrown much light on the antiguity of disease. Thus many affections of bones, arterio-sclerosis, rheumatoid arthritis (2900 B.c.), gout, diental caries and pyorrhoea, pneumonia, gall-stones and renal calculi, bilharziasis, and other still familiar ills that flesh is heir to, have been found in Egyptian mummies. But as regards acute fevers, which from their nature are prone to vary and are much more difficult to identify, help is wanting.

As both nations and their constituent individuals differ in their " constitution" or make-up, partly from heredity and partly as the result of the long-continued influence of their surroundings, their powers of resistance to disease must vary in a corresponding degree. Under certain conditions, such as those of war, famine, and epidemics-for example, of influenza-the vitality of a nation may be so much impaired that factors ordinarily comparatively harmless are enabled to act at an advantage, so that other diseases become frequent. Thus secondary epidemics or diseases which are not in evidence at other-times mav become preralent. This sequence may have suggested to Sydenham his conception of "epidemic constitutions" that is, that during the period of a dominant epidemic other diseases tend to share the characters of that infection. There are, indeed, close analogies between the factors modifying diseases in the course of time and those which appear to be responsible for the outbreaks of epidemics. The diminished resistance of a nation due to the depressing factors-material and mental-inherent in war, destitution, and unemployment, would probably allow micro-organisms previously of comparatively low pathogenic power to become active, and thus help to explain the increased frequency of streptococcal diseases, especially subacute and chronic bacterial endocarditis, and of pernicious anaemia since the great war.

Hereditary deficiency in resistance of the tissues, or of one particular tissue, of races or of individuals may lead to the incidence of particular diseases or to certain forms of those diseases; so that a nervous system weak from congenital defects will favour the attack of an infection, such as that of influenza, on that part of the body-a problem recently discussed by $\mathbf{H}$. P. Newsholme. Hereditary diatheses or morbid proclivities in certain races of mankind lead to the occurrence of special diseases among them; this is best seen in the Jewish nation, which provides most of the cases of amaurotic family idiocy and thrombo-angiitis obliterans; it is further noteworthy that when these diseases do occur in Gentiles tho manifestations are less severe and do not come on so early in life, thus suggesting that the inborn tendency is more powerful in the Hebrew cases. The highly nervous make-up of the Jewish race is a factor in disposing them to diseases of this system.

Influence of Environment.

2. Environment influences disease in many wars. It is so clear that climate is a most potent factor that the effects of heat and cold, humidity, absence of sunlight, need not be laboured: in hot countries the presence of special parasites, particularly protozoa, such as the malarial and amoebic organisms, and their carriers or vectors, such as mosquitos, are responsible for the important group of the tropical diseases. On the other hand, an environment, such as that of isolated races, free from some common infections, such as tuberculosis and measles, leaves the inhabitants a virgin soil; but should the infections be introduced, the incidence and mortality of the cliseases tend to be very high. This is not so much due to want of inuate racial resistance, as might perhaps be thought, but to the widespread absence of any previous individual infection and acquired immunity, or, as Krause persuasively argues, to concomitant changes in the manner of life, approaching those of the more artificial complexities of civilization which lead to physical degeneration of the pure stock of primitive peoples.

Environmental factors are more obviously powerful than heredity in the production of new forms of disease; this was shown, particularly during the great war, by occupational diseases in which the worker is exposed to some poisonous agent, such as trinitrotoluene or tetrachlorethane, in the manufacture of munitions and the varnishing of aeroplane wings with "dope." The branch of Industrial Medicine, already considerably advanced in America, especially in Boston, though originally suggested in this comtry by George Baker (1767), Thomas Pereival (1796), and C. T. Thackrah (1831), and developed by Greenhow (1857), Thomas Oliver, Thomas Legge, and others, supplies many examples 
of trade diseases. Another way in which environment brings about disease is by privation of some essential accessory food factor. Study of the "deficiency diseases" and the discovery of vitamins have opened out the path to the prevention of diseases such as rickets, beri-beri, scurry, and dental caries; and recently vitamin $\mathbf{E}$ has been shown to be essential to fertility, its absence being responsible for sterility.

Among the cnvironmental factors bacteria and protozoa are responsible for the majority of diseases. As they are at the base of the scale of living organisms it may be assumed that they are more prone than the higher animals and man to variation and mutation as the result of influences such as food and temperature; and that, at first purely saprophytic, some of them in course of time become parasitic and pathogenic for man. In its early days bacteriology discomitenanced bacterial variation, and worked its way on the basis of fixity of type among the species of bacteria. It is now known that there is an enormous amount of potential variation in bacteria, and that a present-day hacteriologist " has not only to define tho species of bacterium with which he is working, but the particular form or variant" (Arkwright). Modern work, recently summarized by Dible, shows the morphological, cultural, and serological differences of variants from the normal species-for example, in the Salnonella group (Andrewes; P. Bruce White)-and the probable influence of bacteriophage in promoting variation. The artificial conditions of laboratory cultivation tend to diminish their virulence, though occasionally a reverse action is observed; whereas the passage of pathogenic microbes through a series of animals of the same species enhances their virulence, thus supporting the view long ago expressed by W. H. Welch that bacteria on their part adapt theniselves to their environment, just as the host develops a mechanism of defence against them. Clinically it may be noted that an increase in the severity, and not only in the incidence, of an infectious disease, such as diphtheria, may be noticed when a number of individuals are crowded together, though it is true that lowering of their resistance may play some part in this result.

Differences in the clinical manifestations of enteric (typhoid and paratyphoid) fever, dysenters, cerebro-spinal fever, and to some extent of pneumonia, have been proved by bacteriology to result from infection with different types of the typhoid-paratyphoid group, dysentery bacilli (Shiga and Flexner), meningococci, and pneumococci. This distinction of the type of the infective organism is, of course, of far more than academic interest, for it enables immunological treatment to be scientifically and successfully employed. Further evolution of bacterial variations, such as at some time in the past may have resulted in the formation of paratyphoid from typhoid bacilli, night lead to the production of new forms of disease; at the present time it may well be that there are many such bacterial divisions of disease as yet not separated from each other clinically and so still included under a single nosological label. Aberrant forms of infectious diseases would suggest the existence of variations in the causal agent; but here the possibility that mixed infections play a complicating part must be borne in mind. Just as diseases may die out, such as "the sweating sickness" in England in the fifteenth century, so may new diseases arise; syphilis, it seems safe to assume, did not exist in ancient Rome, as such a careful observer as Gaien did not describe it or its nervous manifestations tabes dorsalis and general paralysis of the insane. But it may be noted that there is good evidence of its existence in Europe before the era of Columbus, and therefore that it was not introduced from tho New World. Amorig animals hog cholera, muknown before the seventies of the last century, when it appeared in the United States of North Anierica, is an example in support of the view that micro-organisms can and do undergo evolution from a harmless saprophytic condition to one of pathogenic activity.

In balancing the two factors-the soil and the seedthat determine the reactions known as disease, it is interesting to follow the swing of opinion's pendulum between their relative importance; seventy years ago the individual's constitution, diathesis, and temperament were regarded as the essential factors in the causation of illness. When bacteriology came on the scene and progressively revealed the true exciting causes of one infective discase after another, it semed probable that every difficulty would be clearly solved, and the doctrine of constitution, the elements of which could not be seen under the microscope, faded away into the background as a misty conception, and for a time into almost complete oblirion. But the discoveries of this early stage of bacteriology naturally led to the careful investigation of the defensive powers of the living body against microbic attack; this study of immunology has brought up again the underlying innortance of the constitutional factor in disease, which is now attracting investigator's in disorders other than those directly due to infection.

The Significance of Disease.

To most minds disease is included in the mystery of evil and considered an unmitigated calamity, and in the past has been regarded as part of a system of rewards and punishments. As the existence of a single micellular organism normally terminates by division into two similar but rejuvenated individuals, these simple cells have been described as immortal, whereas in the higher grades of living creatures death has been regarded as an acquired character, associated with differentiation of the constituent cells and a resulting highly complex mechanism, and as: an adaptation advantageous to the race (Weismann); this last -academic-conclusion has been criticized as probably the most perverse extension erer made of the thevry of natural selection (Pearl). Doath comes either natually by a gradual exhanstion of the innate endurance and vigour, or unnaturally from accident or disease, which are therefore short cuts to deati. From a biological point of view diseases have been regarded as beneficial inasmuch as they weed out the phrsical weaklings and so make for the survival of the fittest and the improvement of the race. Thus disease kills off the vicious, and, to take a rather special cxample, gonorrhea, by sterilizing the prostitute, prevents the propagation of the degenerate; White, indeed, rather unkindly says, "In fact it is open to question whether, taking all things into consideration, the cugenist could (to better." Still, many besides the degenerate fall victims, and disease, which has been at work and on its trial in this respect from or before the dawn of historr, is too rough and unorganized a method to bring about the survival of the fittest. There will thercfore be general agreement with the late Sir Clifford Allbutt's dictum a quarter of a century ago that public health will offect this ohject better and more permanently than puhlic death. It is unnecessary to labour the evils brought hy disease, but it may be well to glance at the other side of the shicld and, though to some this may at first sight seem fanciful, to explore the possibility that disease may have good effects-a contention vigorously supported from a technical standpoint nearly a quarter of a century ago by the late Frederick Treres.

As good may come out of evil, it may bo worth while to summarize briefly the conceivable ways in which disease, on account of associated conditions and of the opposing forces thus brought into play, may be regarded as exerting a beneficial effect. This problem may be reviowed from two aspects: (1) general and sociological, and (2) that of the individual.

Benefieval liffects of Diserese in General.

It is not always easy or indeed possible to draw a hard-and-fast line brtween the normal or henlthy an the one hand, and the ahnormal, which nay tend to proaluce discase or be in itself morbid, on the other hand. There may, in fact, be imocent as well as malignant abmormalities. There is a borderland between health, which Allbutt (1924) spoke of as an oscillation about an idloal axis, and disease, and it has been said that they are both relative terms and that there are various states of hoalth and of disease (W. A. White).

The racial characteristics which, according to Keith, in part depend on the degree of activity of the cndocrine 
glands, may, when exaggerated, become definitely morbid and cause disability. Thus in this country the condition of Mongolian idiocy, first described in 1866 by Langdon Down, the causation of which, though uncertain, may possibly be due to a disturbance of the endocrine balance (Clark, indeed, ascribes it to foetal exophthalmic goitre), reproduces some of the facial characters of the Mongolian race. Pituitary activity, stated to be most obvious among the modern races of the Caucasian or European type, when greatly in excess causes pathological giantism and acromegaly. The occurrence of variations or, more strictly, of "sports" plays a part in the evolution of the race, and among these departures, from the average the line of demarcation may be very thin between those exerting a beneficial influence and those definitely morbid. This is familiar in Dryden's lines:

\section{"Great wits are sure to madness near allied,}

and as regards this particular example it has been shown by the late Sir Frederick Mott and others, from a study of many pedigrees, how real this association is, and that environment and factors so obscure that in our ignorance they are called chance determine whether this inborn tendency will land the individual in the seats of the mighty, a prison, or a mental hospital.

The variations that are responsible for the evolution of the race are accompanied by others that facilitate disease, and though the latter cannot of themselves be regarded as useful, their occurrence is so commonly associated with that of those making for improvement that they may be regarded as a necessary accompaniment.

Genius and outstanding ability, though often and easily confused, are distinct; ability is, as Galton showed sixty years ago, largely hereditary, and may be associated with a family history of mental instability or defect. But, as compared with ability, genius is a finer and extreme development of the imagination and power of correlation, and may extend out of the abnormal into the pathological. The assuciation of genius with disease of the mind and body has no doubt been exaggerated by the statement that a genius is hardly ever healthy; there are, however, abundant examples to support the contention of Lombroso and others that genius is often closely related not only with criminality and insanity but with other morbid conditions of the nervous system; this combination may occur in tho same person, or the association may be shown by evidence of the neuropathic element in the genius's family tree. In the latter instance the genius or specially gifted individual comes of a ncuropathic stock, though not himself necessarily degenerate. Enough has been said to show that genius and mental instability may be regarded as variations from the normal mentality. Their morbid manifestations may occur at different times in the same person, periods of definite insanity supervening and passing off; or insanity when it supervenes may close the career.

Geniuses, being usually highly strung, are certainly not immune to common ailments. While clisease damages and eventually may destroy the body of the gifted individual, it must colour the mental attitude during the progress. While the usual effect of poisons is necessarily deleterious, some of them, especially in the highly sensitive and those with an idiosyncrasy, may in the early stages, when their irritant effect is predominant, cxert a stimulating effect. Alcohol, opium, and morphine, as shown by not a few oxamples, have been the means by which a genius has been helped to deliver his inspired message. Similarly it has been thought that the toxins of disease may so act on the brain as to lead to the production of masterpieces instead of the more frequent nightmares and delirium. Many literary giants have naturally been tuberculous, and it is an obvious suggestion that their eminence may, in greater or less degree, have been due to, rather than in spite of, their infection. It has also been thought that syphilitic toxaemia played a part in the increased output of brilliant work shortly before its destructive triumph over men like Guy de Maupassant, Friedrich Nietzsche, Heinrich Heine, C. P. Baudelaire, and Paul Verlaine.
The occurrence in Nietzsche's Ecce Homo of chapters headed "Why I am so clever" and "Why do I write such good books?" certainly suggests that ho was already in the stage of exaltation of general paralysis of the insane.

It has been argued that, like alcohol and morphine, the bacterial poisons are responsible for striking ideas and conceptions by paralysing the mechanism normally blocking the external manifestations of an underlying creative power or personality (Jacobson). It is tempting to speculate on the correlation of various organic diseases with the characters of the literary and artistic products of the sufferers, and how far any special trait or tone of expression can be regarded as related to a particular disease. Did the hopeful spirit-the spes phthisica-account for the inspiration of some victims of pulmonary tuberculosis, such as Keats, Laurence Sterne, Emily Brontë, and Elizabeth Barrett Browning? There is some evidence from the Vailima Letters that when Robert Louis Stevenson's health improved his literary work deteriorated, and this has bc $\mathrm{n}$ explained by the absence of a toxaemic influence. In other instances, such as Francis Thompson (1859-1907), author of The Hound of Heaven, and Thomas De Quincey, tuberculosis of the lungs has been complicated by alcoholism or opium addiction; and then, as Jeannette Marks says, the question arises of "germs and genius" or "drugs and genius." How far did dyspepsia or, as G. M. Gould insisted, eye-strain guide Thomas Carlyle's mordant pen, and to what extent was Ménière's syndrome, from which Jonathan Swift probably suffered, responsible for his savage wit?

In $80 \mathrm{~m} \theta$ rather special instances an individual's disease has been the means of greatly benefiting his fellow sufferers, as it has made him monstrous kind in the practical sense of providing for their well-being and care; thus Sir Arthur Pearson's (1866-1921) loss of sight was the salvation of the blind in St. Dunstan's, where they were taught not only to earn their living but to bear their cross courageously and cheerfully. Medical men, themselves stricken, have worked for the relief of those with whom they can so fully sympathize: E. L. Trudeau (1848-1910) utilized his own long fight against tuberculosis to promote the open-air treatment of that disease in North America; and it has been said of him that perhaps nothing in the whole field of medicine in the past fifty years in America has done so much directly or indirectly to relieve suffering and extend the years of usefulness of so many people as the principle which Trudeau laid down at Saranac Lake (J. A. Myers). Another example is Mr. Clifford Beers, who, having suffered for years from a severe psychosis, founded the National Conmittee for Mental Hygiene in the United States.

In his pathetically charming Confessio Medici the late Stephen Paget (1855-1926), who suffered much and greatly loved his fellow men, wrote, "You cannot be a perfect doctor till you have been a patient; you cannot be a perfect surgeon till you have enjoyed" (and he proceeds to justify the somewhat unexpected verb) " in your own person some surgical experience." Many examples could be given of medical men who, as the result of their own sufferings, have been able to throw light on the nature, prevention, and cure or alleviation of their own particular cross.

Pain, one of the commonest manifestations of disease and useful as a warning of its presence, may, as James Hinton (1822-1875) the mystic argued; have uses that we know not of, possibly an unconscious though effective martyrdom for others. In his Book of the Sorrowful Hinton was mainly concerned with mental anguish, but with regard to physical pain it may also be wise to admit that there are more things than are dreamt of in our philosophy. Professor Emery Barnes reminds us that "from St. Paul downwards through the ages some of the greatest Saints of God have believed that their bodily sufferings or their bodily weakness has been of immense value in training the spirit."

Lastly, disease, which usually exerts an evil influence on the history of nations, may protect one of two hostile armies from the other by rendering advance and successful 
invasion impracticable, or open the way to occupation of a new land-for example, the "providential" pestilence among the aborigines of Massachusetts Bay (1616-20) which enabled the first Pilgrim Fathers to take possession of the land in safety (Krause).

\section{Beneficial Effects for the Individual.}

A disease may do good by limiting its victim's activities in certain directions, such as social success or athletic prowess, and so leading him to concentrate his energy and powers on some specialized branch of intellectual work; thus by way of compensation he makes good, or achieves even greater success than he would have thought of attempting when unrestricted in his choice of a life's work. Invalidism necessarily restricts vicious selfindulgence and excess in satisfying the lusts of the flesh, and so may protect against the risk of oth $r$ diseases to which the vigorous are, as a result of their rude health, more prone to expose themselves. This mode of protection is analogous to that probably responsible for the great longevity of women as compared with men.

There are other ways in which disease is a blessing, though perhaps in disguise; the onset of a trivial ailment or the detection of the early signs of disease without symptoms, such as are discovered at a routine examination for life assurance, may so impress the individual that he amends his manner of life, greatly to his future advantage. This warning mechanism was well expressed in the title of Sir William Osler's paper on "The advantages of a trace of albumin and a few tube casts in the urine of certain men above 50 year's of age." Another example is the advantage of a raised blood pressure detected in its initial stages, provided steps are duly taken to prevent a further rise which would in time lead to generalized arteriosclerosis and perhaps granular (arterio-sclerotic) kidneys. IVith the progress of medicine to its preventive ideal the logical utility of periodical medical examinations of the adult population will no doubt be recognized, and so lead to the detection of the early warnings and signs of impending disease among those as yet unconscious of anything amiss.

It is not an argument worth labouring, but, as certain conditions or reactions, such as emaciation and obesity, are due to their opposites, such as deficiency and excess, one disease may be the antidote to another, the two being, roughly speaking, incompatible. Thus there is a certain amount of antagonism between tuberculosis and gout, and tuberculosis and obesity. Moreover, as is well recognized, a chronic disease may sometimes appear to provide its own cure in this way; thus exophthalnic goitre may gradually pass into the opposite condition of myxoedema, and acromegaly (hyperpituitarism) may be succeeded by hypopituitarism.

An acute disease may cure a chronic affection; thus pneumonia may, for the time being at any rate, abolish the movements of chorea, or remove a skin disease of long standing; whooping-congh has long been thought to be relieved by vaccination, and has been known to be benefited by an attack of urticaria (Bury). The influence of an acute infection on a (hronic one is probably analogous to the effect of protein shock therapy, in which the injection of a "foreign" protein into the blood stream sets up an acute reaction which in some way increases the protective mechanism against infection; for example, injection of peptone may be followed by much improvement in chronic arthritis. Just as many acute fevers leave behind them immunity for the rest of life, so a modified form of the disease or an abortive attack, which may escape notice at the time, protects the individual from a recurrence of the disease. 'This is well shown in vaccination against small-pox, and by the observation that people who have had the present mild form of small-pox, sometimes called alastrim and para-small-pox, do not contract the disease itself. Many forms of treatment act by stimulating or supplying the reaction and defonsive powers of the patient necessary to repair damage or overcome infection; this was the rationale of Almroth Wright's vaccine theraps, and empirically the method has been emploved for ages. The old practice of inserting a seton in the neck, thus creating a local wound or focus of infection, to cure some chronic condition, the similar production of sterile abscesses -for example, by turpentine-to counteract infections elsewhere, and counter-irritation, such as blistering, to relieve the pain in acute diseases, are examples of the attempt to neutralize the morbid reaction of one infection by another and artificially induced reaction.

\section{The Relation of the Nature of Disease to its Prevention.}

Lastly, with regard to the practical bcaring of the nature of disease: the ideal of Medicine is the prevention of disease, curative treatment being really a tacit admission of failure in this respect. For the prevention of disease knowledge of its causation and nature is obviously essential. The two great factors in the causation of disease are heredity and environment. Heredity of actual infective disease occurs in only a fow instances; but structural and functional defects, especially in the vital resistance, of the body are common and important. Environmental influences cover a wide field, from the gross factors of deficient food, slum dwellings, and general misery, to the ultramicroscopic viruses of infective disease. The preventive measures and remedies, therefore, are correspondingly various. It is unnecessary to refer to the desirability of correcting the economic factors of poverty resulting in unhygienic surroundings, overcrowling, and deficient and bad food and drink; but a word may be said about the importance of universal health education as a means of preventing disease and so preserving the well-being of the nation. The recognition of the need for intellectual education is a duty recognized much earlier by the Government, for it is only since the war, when the Ministry of Health was established, that health education of the masses has really gone ahead. Preventive medicine is every man's business, for it is the active response to the instinct of self-preservation. The distinction, obvious though it be, may perhaps he emphasized hetween the practice of preventive medicine, in which each individual should be his or her own guardian, and the unirersal practice of curative medicine, which is inarlvicalble on account of the inherent dangers when carried cut by laymen. It may woll be that want of a rear dividing line between personal hygiene and domestic medicine has in the past made modiral men hesitate about the advisability of encouraging general instruction in the laws of physiological righteourness, to use Sir Andrew Clark's phrase.

About the fundamental subject of an accurate knowledge of the calusation of disease, on which preventive medicine is hased, there is yet much to learn. As Sir George Newmail has pointed out, it is extraordinary what contributions to medicine have in the past been made by scientific men who were not nembers of the medical profession. The deht of medicine to the more cxact sciences mounts up much more rapidly and is much more in evidence now than ever before, and it is obvious that there should therefore be the closest possible association and correlation betwcen the scientific workers in laboratories, where discoveries are made and tested, and the clinicians in the wards of hospitals, where the practical application of new knowledge may lead to firsh advances in the prevention as well as the cure of discase. With the specialization inevitable from the enormous advance of knowledge there is an infortumate tendency for these two classes of workers to plongh their own furrows; guidance from men of pure science is of the greatest value in the discovery of the causes and nature of disease; for physies and chemistry, biochemistry, physiology, and pathology touch, overlap, and interlace with each other, and human biology is a good synonym for medicine. To facilitate this desired association much can be done by the plan of having the various science laboratories in the same building or all concentrated together; the physiological, biochemical, anatomical, and pathological departments close to and communicating with the hospital, just as the physies department is or should be a near neighbour of the engineering laboratory. The University should have control of the hospital as well as of the laboratories-a conception not perhaps yet widely accepted. 
REPERENCES.

Adami, J. G. : The Principles of pathology, 1910, i, 22

Idem : System of Medicine (Allbutt), 18\%

Allbutt, T. C. : British Medical Journal, 1871, ii, 416 ; Lancet, 1906, ii, 1105 dem : $\Lambda$ didress to Section I of the Sanitary Institute, XXI Congress at Bradford in 1903

Idem : Times, November 6th, 1924

Andrewes, F. W.: Journ. P'ath. and Bact., Edin., 1922, xxv, 505; 1925,

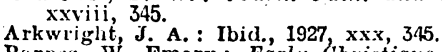

Barnes, W. Emery: Early Christians at l'rayer (1.D. 1-400), pp. 68-69, London, Methuen and Co., 19-5.

Bland-Sutton, J.: Evolution and Discase, 1890, Contemporary Scicnce

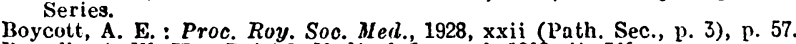

Broadbent, W. H. : British Medical Journal, 1868, ii, 346.

Bury, J. S. : Med. Chron., Manchester, 1907, xlyi, 277.

Clark, R. A. Journ Mental Sci. Journal, 1927, ii, 1006.

Crookshank, F. G.: Articles in Influenza, London, 1922

Dible, J. H.': Recent Alvances in Bacterinlogy, pp. 34-84, Iondon, 1929.

Galton, F.: Hereditary Genius: An Enquiry into its Laus and Con-

Caskell, A. : What is Life? London, 1928.

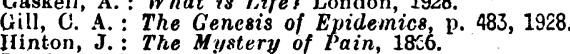

acobson, A. C. : Genius, Some Revelations 1926

Jones, Handfield : British Medical Journal, 1868, ii, 68, 345

Keith, A.: Bull. Johns Hopkins Hosp.. Baltimore, 1922, Xxx, 155. Journ.

Krause, A. K.: Amer. Rev. Tuberc., Baltimore, 1928, xviii, 208. Ibid., xviii, 27 .

Langdon Down: London Ho8p. Rep., 1866, iii, 259.

Lumière, A.: La vie, la maladie, et la mort: phénomènes colloülaux, Paris, $19 \dot{\text { à }}$

McDonagh, J. E. R. : The Nature of Disease, Part I, 1924; Part II, 1927.

Marks, J.: Genius and Disaster, p. 187, 1928

Mercier, O. A.: Science Progre8s, London, 1916-17, xi, 228, 410.

Jlott, F. W. : Charing Cro88 Hosp. Gaz., 1923, xaii, 11

Myers, J. A.: Fighters of Fate, 1927.

Newsholme, H. P.: Proc. Roy. Snc. Merl., 1928, xxii (Evidem. Sect.), 1.

Osler, W. : New York Med. Journ., 1901, Ixxiv, 949.

laget, S. : Confessio Medici, 1908.

Pearl, R.: The Biology of Death, p. 43, 1922

reves, F.: British Medical Journal, 1905, ii, 1251

W. H.: Adaptation in Pathological Processes, Amer, Journ. Med. Sci., Phila., 1897, cxiii, 631

P. B. : Medical Research Council, Special Report Series, No. 103,

W. The Meaning of Disease, p. 107, $19 \geq 6$.

Wilks, S.: British Mctlical Journal, 1868, ii, 136.

\section{VOLVULUS OF THE INTESTINE. BY}

\section{R. P. ROWLANDS, M.S., F.R.C.S., SURGEON, GUY'S HOSPITAL.}

Volvulos rotation or twist may affect any of the movable viscera, and this accident is especially likely to happen to thoso organs or parts which aro pendulous or more or less pedunculated, such as the pelvic colon, caecum, spleen, retained testis, ovarian cyst, or subperitoneal fibroid. The weight of a tumour, a distended Meckel's diverticulum, or a mesenteric cyst, or the drag of a peritoneal adhesion may start or complete the twist. I have seen several instances of volvulus of the spleen of the omentum, of the gallbladder causing sloughing, and one instance of rotation of a loose liver causing jaundice by kinking of the bile ducts. Even the stomach is not immuno from volvulus; being fixed as it is at the cardia and pylorus, the dilated or distended intervening portion may twist, especially when it is dragged upon by a large spleen or escapes into a diaphragmatic hernia; serious and acute pyloric obstruction has arisen in these ways, and has been relieved by replacement and removing the cause.

In this article I am chiefly concerned with rolvulus of the intestine causing intestinal obstruction. Such a volvulus may be acute, chronic, or recurrent; it may be simple, affecting only one loop of bowel, or it may be compound, as when a loop of small intestine twists roind a volvulus of the pelvic colon. ${ }^{1}$ Any part, or the whole, of the small intestine ${ }^{2}$ except the duodenum, and any part, or even the whole, of the large intestine except the rectum, may twist (Finney recorded a volvulus of the whole of the colon between the ileo-caecal valve and the pelvic colon ${ }^{3}$, but the common sites of the volvulus are tho pelvic (sigmoid) colon and the caecum. Congenital imperfections, especially elongation of the mesentery, such as a long mesosigmoid with a narrow base, or a pendulous and freely movable caecum and ascending colon, aro usually determining factors. Visceroptosis with distension and elongation of the pelvic colon associated with chronic constipation, and repeated prolapse of the rectum, also contribute to the causation of volvulus. Injuries, violent twisting movements, and operations may displace and twist the bowels-for instance, the pelvic colon was raised and displaced to the right during an operation for ruptured left extrauterine foetation, the loop was not replaced, and fatal volvulus resulted. The consequences of volvulus are often grave, for obstruction of the vessels may lead to swelling, haemorrhage or infarction, inflammation, and necrosis or gangrene of the twisted loop, thus adding to the dangers of intestinal obstruction. Volvulus of the appendix and of Meckel's diverticulum* often causes severe attacks of inflammation, or gangrene of the twisted part, with peritonitis and ileus.

\section{Symptoms of Acute Volvulus.}

The symptoms, and signs of acuto volvulus, whether of the large or small intestine, are those of acute intestinal obstruction, such as severe spasmodic abdoninal pain, characteristic vomiting, complete constipation and collipse, with slow weak pulse and subnormat tenperature. Here it is only necessary to point out the special features of volvulus. The history of previous attacks is very suggestive of volvulus, the more acute the case the more severe the pain, and, above all, the more rapid and extreme the distension of the abdomen the more is volvulus to bo suspected. Visible peristalsis, when observed, in very large coils is almost characteristic of volvulus of the large intestine, but it is not by any means constant. Volvulus is commoner in the large than in the small intestine, anc is especially common in the pelvic colon. With volvulus of the small intestine tho coils are naturally smaller anc? the distension less phenomenal, but the severity of the symptoms is usually extreme, and the march of events to a fatal issue is more rapid unless relief is brought by early operation.

Syarptoms of Chronic and Recurrent Volvulus.

These are chiefly those of chronic intestinal obstruction -namely, recurrent attacks of colic with distension, indigestion, and chronic constipation perhaps alternating with diarrhoca, but without blood in the stools. Fever is usually absent. Sometimes the bowels do not act without the aid of large doses of violent purgatives or enemata or both. Opaque meals, and especially a barium enema, may reveal great dilatation and stagnation in the affected loop. An opaque meal is more valuable with chronic incomplete volvulus of the caecum, for an opaque enema may not reach or enter the obstructed loop as the obstruction is more complete at the distal than at the proximal end of the loop. An opaque enema is usually more valuable in the diagnosis of volvulus of the pelvic colon.

\section{Diagnosis of Acute Volvulus.}

From other kinds of intestinal obstruction volvulus is to be distinguished chiefly by the very acute onset, rapid progress of the symptoms, and particularly by the unusual amount of tympanitic distension of the abdomen, which develops in a very short time. As already mentioned, visible peristalsis in very large coils of intestine is suggestive of volvutus of the large intestine; the twisted dilated caecum is often to be seen lying in the left iliac fossa, and the twisted and distended pelvic colon in the right hypochondrium. There is of ten a history of previous attacks of colic without fever; the absence of fever tends to exclude recurrent appendicitis, cholecystitis, and diverticulitis. Volvulus of the large intestine is naturally most likely to be mistaken for the far commoner cause of obstruction of the colon-namely, carcinoma of the colon, which causes considerable, but less rapid, gascous distension. With carcinoma there may be a history of chronic constipation alfernating with drarrhoea, with blood and mucus in the stools. Often the diagnosis is not ertain until the abdomen is opened, as it should be without delay.

Diagnosis of Chronic Volvulus.

Here there is more time and opportunity for investigation. Chronic and recurrent volvulus is most commonly mistaken for chronic constipation, but careful and repeated radiographic examinations may reveal the dilated coils so

* An interesting and successful case of volvulus of a greatly distender Meckel's diverticulum is recorded in The Operations of Surgcry Rowlands and Turner, scventh edition, ii, p. 344 . 